\title{
PENGGUNAAN STRATEGI PEMBELAJARAN AKTIF EVERYONE IS A TEACHER HERE (ETH) TERHADAP KEMAMPUAN PEMAHAMAN KONSEP MATEMATIKA SISWA KELAS VII
}

\author{
Sri Yunita Ningsih ${ }^{1}$, Gustimalasari ${ }^{2}$ \\ ${ }^{1}$ Program Studi Pendidikan Matematika STKIP Insan Madani Airmolek \\ ${ }^{2}$ Mahasiswa Program Studi Pendidikan Matematika STKIP Insan Madani Airmolek \\ ${ }^{1}$ sriyunitaningsih89@gmail.com
}

\begin{abstract}
This research has been made to know skill of student's concept by using active learning strategy everyone is teacher here (ETH). Beside that this study aims to measure student's concept understanding with statistical test between Experimental Class (Active Learning Strategy Everyone Is Teacher Here) and control class (Conventional Learning ). The population was seven ${ }^{\text {th }}$ grade of SMPN 3 Lirik consist 94 students in three classes. Sample was took randomly, experiment class (VII.2) and control class (VII.I) This research was experiment, the form of this research was Quasi Experimental Design with randomized subject posttest only control group design. based on statistic data processing has been retrieved - $t$ hitung $-3,159$ smaller than $-t_{\text {table }}$ was $-2,000$ and based on $t_{\text {test }}$ has been retrieved $-t_{\text {hitung }}<-$ $t_{\text {table }}$ so $H_{o}$ rejected and $H_{a}$ received. So that the writer conclude that skill of math student's concept understanding by using active learning Strategy Everyone Is Teacher Here (ETH) is better than conventional concept understanding.
\end{abstract}

Keywords: Everyone Is A Teacher Here, Concept Understanding

\begin{abstract}
Abstrak. Tujuan penelitian ini adalah untuk mengetahui kemampuan pemahaman konsep siswa dengan menggunakan strategi pembelajaran aktif Everyone Is A Teacher Here (ETH). Salain itu, penelitian ini juga ditujukan untuk mengukur pemahaman konsep siswa dengan uji statistik antara kelas eksperimen (Strategi Pembelajaran Aktif Everyone Is A Teacher Here) dan kelas kontrol (Pembelajaran Konvensional). Populasi siswa kelas VII SMP Negeri 3 Lirik 94 orang yang tediri dari 3 kelas, sedangkan sampel penelitian diambil secara random sampling, kelas eksperimenya (VII.2) dan kelas kontrol (VII.1). Jenis penelitian ini adalah penelitian eksperimen. Bentuk penelitian yang digunakan adalah Quasi Eksperimental Design dengan desain Randomized Subjects Posttest Only Control Group Design. Berdasarkan pengolahan data secara statistik dipeoleh - $t_{\text {hitung }}$ sebesar $-3,159$ lebih kecil dari - $t_{\text {tabel }}$ sebesar 2,000 dan berdasarkan uji $t$ diperoleh $-t_{\text {hitung }}<-t_{\text {tabel }}$ maka $\mathrm{H}_{0}$ ditolak dan $\mathrm{H}_{\mathrm{a}}$ diterima. Sehingga dapat disimpulkan bahwa kemampuan pemahaman konsep matematika siswa dengan menggunakan strategi aktif Everyone Is A Teacher Here (ETH) lebih baik dari pada kemampuan pemahaman konsep dengan menggunakan pembelajaran konvensional (biasa)
\end{abstract}

Kata Kunci : Everyone Is A Teacher Here, Pemahaman Konsep.

\section{PENDAHULUAN}

Pendidikan adalah salah satu bentuk perwujudan kebudayaan manusia yang dinamis dan sarat perkembangan. Matematika merupakan ilmu yang perlu dipahami oleh setiap orang, terutama siswa yang berada pada jenjang pendidikan formal. Sedangkan hakikat dari matematika adalah siswa dihadapkan dalam belajar matematika pada masalah tertentu berdasarkan konstruksi pengetahuan yang diperolehnya ketika belajar dan akan berusaha memecahkannya. Menurut Suherman (2003:58) yang menyatakan bahwa "Tujuan matematika adalah mempersiapkan siswa agar dapat menggunakan matematika dan pola pikir matematika dalam kehidupan sehari-hari dan dalam mempelajari berbagai ilmu pengetahuan. 
Jihad (2008) menjelaskan bahwa dapat diidentifikasi bahwa matematika jelas berbeda dengan mata pelajaran lain dalam beberapa hal berikut, yaitu: a) objek pembicaraannya abstrak, sekalipun dalam pengajaran di sekolah anak diajarkan benda kongkrit, siswa tetap didorong untuk melakukan abstraksi; b) pembahasan mengandalkan tata nalar, artinya info awal berupa pengertian dibuat seefisien mungkin, pengertian lain harus dijelaskan kebenarannya dengan tata nalar yang logis; c) pengertian/konsep atau pernyataan sangat jelas berjenjang sehingga terjaga konsistennya; d) melibatkan perhitungan (operasi); dan e) dapat dipakai dalam ilmu yang lain serta dalam kehidupan sehari-hari.

Salah satu dari tujuan pembelajaran matematika yang harus dimiliki oleh siswa adalah kemampuan pemahaman konsep. Pemahaman konsep merupakan kemampuan siswa untuk memahami suatu materi pelajaran dengan pembentukan pengetahuannya sendiri dan mampu mengungkapkan kembali dalam bentuk lain yang mudah dimengerti serta mengaplikasikannya. Menurut Van de Walle (2008) pemahaman didefinisikan sebagai ukuran kualitas dan kuantitas hubungan suatu ide yang telah ada. Tingkat pemahaman bervariasi. Pemahaman tergantung pada ide yang sesuai yang telah dimiliki dan tergantung pada pembuatan hubungan baru antara ide. Sedangkan menurut Munandar (2012) pemahaman adalah kemampuan untuk mengingat dan menggunakan informasi tanpa perlu menggunakannya dalam situasi baru atau berbeda. Menerjemahkan, menafsirkan, dan memperhitungkan atau meramalkan kemungkinan termasuk keterampilan pemahaman. Hudoyo (1998:153) bahwa pembelajaran matematika itu memerlukan pemahaman terhadap konsep-konsep. Pemahaman konsep mempengaruhi tingkat keberhasilan siswa dalam belajar matematika, jika pemahaman konsep matematika siswa rendah, akan sulit untuk menguasai aspek lain, yang akan mengakibatkan rendahnya tingkat keberhasilan siswa.

Salah satu penyebab mengapa siswa menganggap matematika itu sulit karena siswa belum memahami konsep dari materi-materi yang sedang dipelajari. Sehingga siswa mengalami kesulitan dalam belajar materi selanjutnya. Pemahaman dalam pembelajaran matematika sudah seharusnya ditanamkan kepada setiap siswa oleh guru yang berperan sebagai pendidik. Karena, tanpa pemahaman siswa tidak dapat mengaplikasikan prosedur, konsep ataupun proses. Belajar matematika bukan dimulai dari menghafalkan rumus-rumus yang jumlahnya tak terhitungkan. Namun, inti dari pembelajaran matematika yaitu pemahaman konsepnya.

Pada umumnya pembelajaran matematika yang diajarkan disekolah masih menggunakan metode ceramah, tanya jawab dan penugasan. Media yang digunakan yaitu media papan tulis saja. Materi pembelajaran berlangsung dengan cara yang sama. Kondisi pembelajaran seperti ini apabila dilanjutkan terus-menerus akan mengakibatkan kejenuhan dan rasa bosan bagi siswa, maka akan berakibat pemahaman materi matematika siswa rendah. Berdasarkan hasil wawancara dan observasi yang peneliti lakukan di SMP Negeri 3 Lirik terlihat dari gejala-gejala: Proses pembelajaran yang dilakukan masih menggunakan pembelajaran yang konvensional, peran guru sangat dominan, sehingga peran siswa dalam pembelajaran kurang terlihat. Pada proses belajar mengajar siswa bersifat pasif sehingga siswa tidak ikut terlibat aktif dalam proses pembelajaran.

Siagian (2017) menjelaskan bahwa suatu pemahaman diperoleh oleh siswa melalui suatu rangkaian proses yang dilalui oleh siswa saat belajar dan interaksi yang terjadi saat belajar bersama orang lain, sehingga siswa dapat membentuk pengetahuan dan pemahaman dari apa yang dialaminya. Oleh karenanya dalam proses pembelajaran matematika guru dituntut untuk mampu memilih metode, strategi ataupun model yang tepat dalam menyampaikan materi pelajaran sehingga apa yang menjadi tujuan dan harapan pembelajaran dapat terwujud dengan baik. 
Untuk mengatasi masalah di atas, maka peneliti perlu diterapkan pembelajaran yang tepat, agar dalam proses pembelajaran siswa lebih aktif dan termotivasi untuk belajar matematika, Sehingga dapat meningkatkan kemampuan pemahaman konsep siswa dalam pembelajaran matematika. Salah satu alternatif yang diduga dapat mengatasi masalah di atas adalah strategi pembelajaran aktif Everyone Is A Teacher Here (ETH). Menurut Uno (2011:75) salah satu aspek yang sangat mempengaruhi adalah cara seorang guru dalam melaksanakan pembelajaran. Kecenderungan pembelajaran saat ini masih berpusat pada guru dengan bercerita atau berceramah. Siswa kurang terlibat aktif dalam proses pembelajaran. Akibatnya tingkat pemahaman siswa terhadap materi pelajaran rendah. Silberman (2009:171) yang menyatakan Strategi ETH ini merupakan sebuah strategi yang mudah guna memperoleh partisipasi kelas yang besar dan tanggung jawab individu. Strategi ini memberikan kesempatan kepada setiap peserta didik untuk bertindak sebagai seorang pengajar terhadap peserta didik lain.

Everyone Is A Teacher Here (ETH) adalah salah satu teknik intruktusional dari belajar aktif (active Learning) yang termasuk dalam bagian pembelajaran dengan rekan sebaya (peer teaching). Tipe ini memberikan kesempatan kepada siswa untuk bertindak sebagai guru bagi siswa lainnya. Ini sesuai yang dikatakan Silberman bahwa sebagian pakar percaya bahwa sebuah mata pelajaran baru benar-benar dikuasai ketika si pembelajaran mampu mengajarkannya kepada orang lain.

\section{METODE}

Penelitian ini merupakan penelitian eksperimen. Bentuk penelitian Quasi Eksperimental Design dengan desain Randomized Subjects Posttest Only Control Group Design. Populasi adalah keseluruhan subjek penelitian. Populasi dalam penelitian ini adalah seluruh siswa kelas VII SMP Negeri 3 Lirik. Yang terdiri dari 3 kelas dengan jumlah keseluruhan yaitu 94 orang siswa. Dimana kelas VII.1 berjumlah 32 orang siswa, kelas VII.2 berjumlah 30 orang siswa, dan kelas VII.3 berjumlah 32 orang siswa. Sampel adalah sebagian atau wakil populasi yang diteliti. Dalam penelitian ini dibutuhkan dua kelas sampel yaitu kelas eksperimen (VII.2) dan kelas kontrol (VII.1).

Teknik analisis data yang digunakan dalam penelitian ini adalah analisis statistik. Teknik analisis data dalam penelitian ini bertujuan untuk menguji kebenaran hipotesis yang diajukan dalam penelitian. Pengujian hipotesis ini menggunakan t-test. Uji t ini bertujuan untuk menguji hipotesis sebagai upaya penarikan kesimpulan dari uji perbedaan antara dua kelompok sampel dalam penelitian ini.

\section{HASIL DAN PEMBAHASAN}

Rata-rata tes kemampuan pemahaman konsep matematika siswa kelas eksperimen dan kelas kontrol dapat dilihat pada tabel berikut ini.

Tabel 1. Rata-rata Hasil Tes Kemampuan Pemahaman Konsep Matematika Siswa

\begin{tabular}{cccc}
\hline Kelas & $\mathbf{N}$ & $\sum$ & $\overline{\boldsymbol{x}}$ \\
\hline Eksperimen & 30 & 2219 & 82,18 \\
\hline Kontrol & 32 & 2031 & 70,03 \\
\hline
\end{tabular}

Dari tabel 1 terlihat bahwa terdapat perbedaan nilai rata-rata hasil tes akhir kelas eksperimen dan kelas kontrol. Rata-rata yang diperoleh kelas eksperimen adalah 82,18 sedangkan rata-rata kelas kontrol adalah 70,03. Terlihat bahwa rata-rata kelas eksperimen lebih tinggi dari pada kelas kontrol. Dengan demikian, dapat disimpulkan bahwa hasil tes kemampuan pemahaman konsep matematika siswa di kelas eksperimen lebih tinggi dari hasil tes kemampuan pemahaman konsep matematika siswa di kelas kontrol. 
a. Uji Normalitas

Uji normalitas dilakukan dengan cara Uji Liliefors. Uji Liliefors dilakukan bertujuan untuk melihat apakah sampel berdistribusi normal atau tidak. Uji ini dilakukan pada kedua sampel yaitu kelas eksperimen dan kelas kontrol. Hasil perhitungan uji normalitas kedua sampel dapat dilihat pada tabel 11 berikut.

Tabel 2. Hasil Perhitungan Uji Normalitas Kedua Kelas Sampel

\begin{tabular}{ccc}
\hline Sampel & Nilai Sign. & Distribusi \\
\hline Eksperimen & 0,200 & Normal \\
\hline Kontrol & 0,200 & Normal \\
\hline
\end{tabular}

Dari tabel 2 terlihat bahwa nilai signifikan pada kelas eksperimen adalah 0,200 dan kelas kontrol adalah 0,200. karena nilai signifikan pada kedua sampel lebih besar dari $\alpha=$ 0,05 maka dapat disimpulkan bahwa kedua sampel berdistribusi normal.

b. Uji Homogenitas

Uji Homogenitas dianalisis dengan menggunakan Uji F. Uji homogenitas bertujuan untuk melihat apakah kedua sampel mempunyai variansi yang homogen atau tidak. Hasil perhitungan uji normalitas kedua sampel dapat dilihat pada tabel 3 berikut.

Tabel 3. Hasil Perhitungan Uji Homogenitas Kedua Kelas Sampel

Test of Homogeneity of Variances

Nilai_Posttest

\begin{tabular}{rrrr}
\hline Levene Statistic & df1 & df2 & Sig. \\
\hline .405 & 1 & 60 & .527 \\
\hline
\end{tabular}

Berdasarkan uji homogenitas variansi dengan statistic diperoleh signifikansi 0,527. Hasil analisis menunjukkan bahwa sig. $(0,527)>\alpha(0,05)$, berarti hipotesis nol nya diterima dengan kesimpulan bahwa populasi bersifat homogen.

c. Uji Hipotesis

Setelah sampel berdistribusi normal dan memiliki variansi yang homogen maka dilanjutkan dengan uji hipotesis dengan cara menggunakan Uji-t. Berdasarkan hasil perhitungan diperoleh $t_{\text {hitung }}=-3,569$. Jika $-t_{\text {hitung }}<-t_{\text {tabel }}$ atau $t_{\text {hitung }}>t_{\text {tabel }}$ maka $H_{0}$ ditolak. Nilai $-\mathrm{t}_{\text {hitung }}<-\mathrm{t}_{\text {tabel }}(-3,569<-2,000)$ maka $\mathrm{H}_{0}$ ditolak. Maka dapat disimpulkan bahwa "kemampuan pemahaman konsep matematika siswa dengan menggunakan strategi aktif Everyone Is A Teacher Here (ETH) lebih baik dari pada kemampuan pemahaman konsep dengan menggunakan pembelajaran konvensional (biasa) pada kelas VII SMP Negeri 3 Lirik”.

Kemampuan pemahaman konsep matematika siswa yang diajarkan dengan menggunakan strategi Everyone Is A Teacher Here (ETH) lebih baik dari pada kemampuan pemahaman konsep siswa yang diajarkan dengan menggunakan pembelajaran konvensional. Hal ini dapat dilihat dari hasil tes kemampuan pemahaman konsep matematika sisiwa pada kelas eksperimen dan kelas kontrol. Pada hasil akhir dilihat dari nilai posttest salah satu siswa dari masing-masing kelas eksperimen dan kelas kontrol dapat dilihat pada gambar 1 dan gambar 2 dibawah ini. 


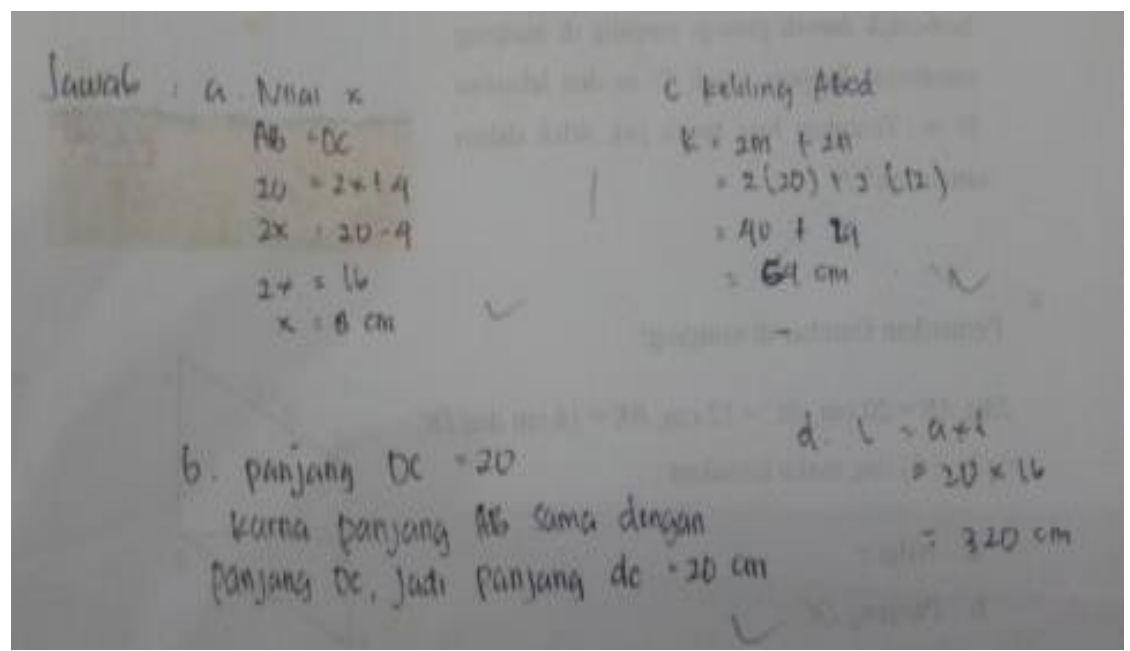

Gambar 1. Jawaban Salah Seorang Siswa pada Kelas Eksperimen

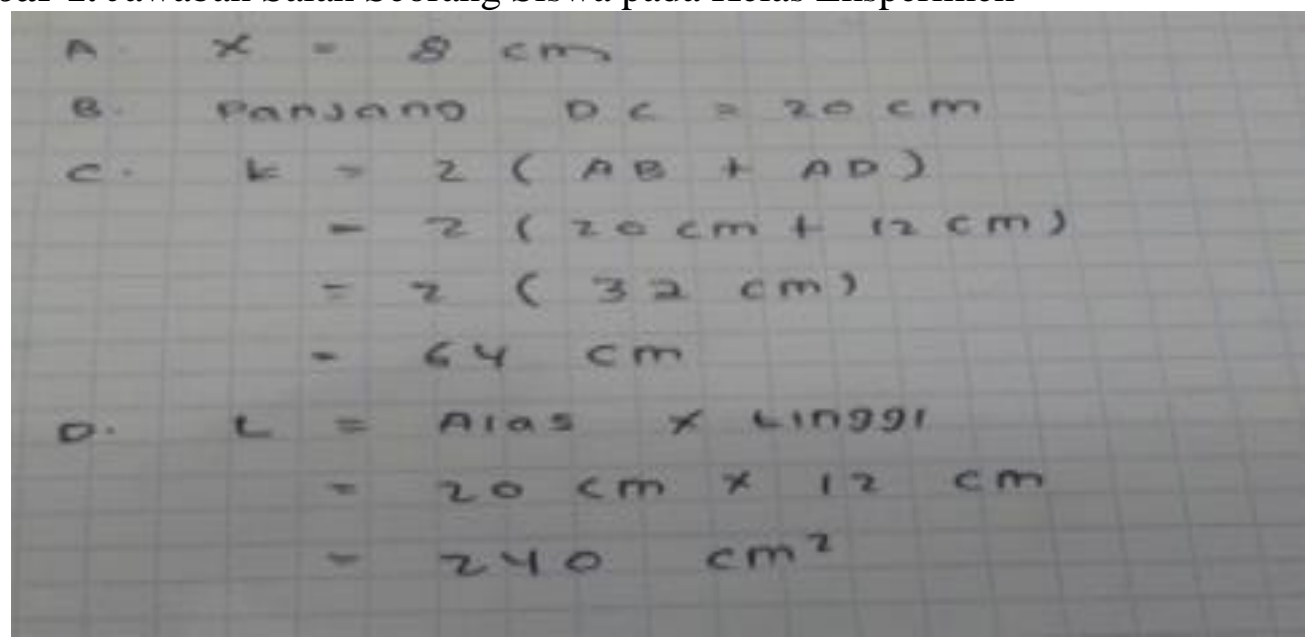

Gambar 2. Jawaban Salah Seorang Siswa pada Kelas Kontrol

Dari jawaban-jawaban antara kelas eksperimen dan kelas kontrol maka dapat disimpulkan bahwa kemampuan pemahaman konsep matematika yang diterapkan pada kelas eksperimen lebih baik dari pada kemampuan pemahaman konsep matematika yang diterapkan pada kelas kontrol. Hal ini juga dapat melatih siswa agar siswa tidak hanya terfokus pada apa yang diberikan oleh guru, namun siswa juga dapat mengetahui pembelajaran melalui pengetahuan yang diberikan oleh siswa lainnya dalam kelompok. Ini sesuai dengan langkah-langkah strategi pembelajaran aktif Everyone Is A Teacher here (ETH) yaitu memberikan kesempatan kepada siswa untuk bertindak sebagai guru bagi siswa lain. Ini akan meningkatkan pemahaman siswa.(Risnawati, 2008) siswa yang memiliki kemampuan lebih bisa mengajarkan kepada teman kelompoknya masing-masing.

Hal ini sejalan dengan hasil penelitian Marhayati (2018) pemahaman konsep dan kemampuan komunikasi matematis siswa yang diajar dengan strategi pembelajaran aktif tipe ETH lebih tinggi daripada siswa yang diajar dengan strategi pembelajaran konvensional, pemahaman konsep siswa yang berkemampuan awal tinggi dan sedang yang diajar dengan strategi pembelajaran aktif tipe ETH lebih tinggi dari siswa yang diajar dengan pembelajaran konvensional, sedangkan pemahaman konsep siswa yang berkemampuan awal rendah yang diajar dengan strategi pembelajaran aktif tipe ETH sama dengan siswa yang diajar dengan pembelajaran konvensional. 


\section{KESIMPULAN}

Kesimpulan dari hasil penelitian adalah kemampuan pemahaman konsep matematika siswa dengan menggunakan strategi pembelajaran aktif Everyone Is A Teacher Here (ETH) lebih baik dari pada kemampuan pemahaman konsep matematika siswa dengan menggunakan pembelajaran konvensional.

\section{SARAN}

Berdasarkan hasil penelitian yang diperoleh, maka peneliti dapat mengemukakan beberapa saran yaitu diharapkan pada guru matematika agar dapat menggunakan strategi pembelajaran Everyone Is A Teacher Here (ETH), karena strategi pembelajaran ini dapat meningkatkan kemampuan pemahaman konsep matematika siswa, bagi peneliti-peneliti berikutnya yang tertarik dengan strategi pembelajaran Everyone Is A Teacher Here (ETH) dapat memperhatikan manajemen waktu pelaksanaan pembelajaran dengan manajemen kelompok., diharapkan kepada guru bidang studi selain dari matematika agar dapat menggunakan pembelajaran Everyone Is A Teacher Here (ETH) pada pembelajaran, karena model ini menuntut agar siswa dapat saling bekerja sama dan bertukar pendapat didalam kelompoknya

\section{DAFTAR PUSTAKA}

Darmadi, H. 2013. Metode Penelitian Pendidikan dan Sosial. Bandung: Alfabeta.

Hudoyo, H. 1998. Mengajar Belajar Matematika. JICA: Depdikbud.

Jihad, A. 2008. Pengembangan Kurikulum Matematika. Yogyakarta: Multi Pressindo.

Marhayati, L. 2018. Pengaruh Strategi Everyone Is Teacher Here Terhadap Pemahaman Konsep Dan Kemampuan Komunikasi Matematis Siswa SMA SPP Dr. M. Natsir Alahan Panjang. Journal of RESIDU,2(6), 50-57.

Munandar, U. 2012. Pengembangan Kreativitas Anak Berbakat. Jakarta: Rineka Cipta.

Risnawati. 2008. Strategi Pembelajaran Matematika. Pekanbaru: Suska Pres.

Siagian, M. D. 2017. Pembelajaran Matematika Dalam Persfektif Konstruktivisme. NIZHAMIYAH (Jurnal Pendidikan Islam dan Teknologi Pendidikan), VII(2), 61-73.

Silberman, M. L. 2009. Active Learning 101 Cara Belajar Siswa Aktif. Yogyakarta: Pustaka Insan Madani.

Suherman, E. 2003. Evaluasi Pembelajaran Matematika. Bandung: UPI.

Uno, H. B. 2011. Belajar Dengan Pendekatan PAIKEM. Jakarta: PT Bumi Aksara.

Van de Walle. 2008. Elementary and Middle School Mathematics. (Alih bahasa Suyono). Jakarta: Erlangga. 